Psychotherapy in pop song lyrics

Running head: Psychotherapy in pop song lyrics

\title{
'That boy needs therapy’: Constructions of psychotherapy in popular song lyrics
}

\section{Miltiades Hadjiosif ${ }^{1}$ and Adrian Coyle ${ }^{2}$}

${ }^{1}$ Department of Health \& Social Sciences, University of the West of England, Bristol, UK, and Scholar of the Alexander S. Onassis Public Benefit Foundation

${ }^{2}$ Department of Psychology, Kingston University London, UK

Corresponding author: Dr Miltiades Hadjiosif, Department of Health \& Social Sciences, University of the West of England, Frenchay Campus, Bristol BS16 1QY, UK. Email: miltos.hadjiosif@uwe.ac.uk

Miltiades Hadjiosif is a Chartered Counselling Psychologist and a Scholar of the Alexander S Onassis Public Benefit Foundation. He is Senior Lecturer in Counselling Psychology at the University of the West of England and sits on the Committee of the British Psychological Societ’s Community Psychology Section. His research focuses on discursive dimensions of psychotherapeutic constructs.

Adrian Coyle is Professor of Social Psychology at Kingston University London. His areas of research expertise concern identity, psychology and religion, loss and bereavement, and qualitative research methods. With Evanthia Lyons, he was co-editor of Analysing Qualitative Data in Psychology (SAGE, 2016).

\section{Acknowledgements}

We would like to thank three anonymous reviewers for their helpful comments on an earlier version of this paper. Our heartfelt appreciation goes to our key informants for their time and enduring interest in our work. Special thanks to Giannis Papazachos for sound mixing an audio clip to play at conferences where we have presented a version of this paper.

Word count: 6729 (excluding references and Appendix) 


\title{
'That boy needs therapy’: Constructions of psychotherapy in popular song lyrics
}

\author{
Abstract \\ Despite a plethora of academic and clinical descriptions of psychotherapy, less research \\ attention has been focused on the ways in which psychotherapy is talked about and \\ represented in popular culture. This study investigates constructions of psychotherapy in the \\ lyrics of popular songs and identifies the vocabularies, versions and relevant discourses that \\ are invoked or crafted. A critical discourse analysis was applied to 24 songs and yielded three \\ broad themes: 'Banal therapy', the 'Non-therapeutic relationship’ and 'I know therefore I \\ can'. These discursive objects are examined in light of a constructionist understanding of \\ knowledge and power within a discussion of how their interplay is implicated in the status of \\ psychotherapeutic concepts and practices as ‘expert knowledge’. Some clinical implications \\ are attended to without making claims that this study has identified ontological \\ representations of psychotherapy in popular culture.
}

\section{Keywords}

discourse analysis, popular music, psychotherapy, social constructionism, song lyrics 


\section{Introduction}

Therapeutic practitioners have directed considerable attention to exploring questions of what psychotherapy is, how it should be done 'properly' and what makes a 'good-enough' therapist. There is a wealth of texts, techniques and clinical insights on these matters (for example Bor \& Watts, 2016; Bugental, 1992; Goodheart, Kazdin \& Sternberg, 2006; Howard, 2010; McLeod, 2013) but such concerns may focus attention away from a systematic consideration of broad cultural narratives of psychotherapy. There is a relative lack of literature on this topic: although there are studies of client expectations, less attention has been paid to lay conceptions and representations of psychotherapy and how our culture crafts these (Furnham, 2009; Furnham \& Wardley, 1990). If we accept that the contemporary therapeutic subject can be constituted by and become mired in conflicting categories or objects that are managed in discourse, there is a need to examine how these objects are framed and communicated through cultural resources. To extend the disciplinary conversation regarding the social embeddedness of therapeutic knowledge, this paper identifies and provides commentary on discursive objects pertaining to psychotherapy that are implicated in the lyrics of 'pop songs'.

Popular narratives of psychotherapy tend to be located within a broad climate of public scepticism towards the discipline of psychology (Lilienfeld, 2012). Moreover, research on ‘mental health literacy’ (Jorm, 2000) in Western countries has found a discrepancy between expert and lay understandings (Furnham, Daoud \& Swami, 2009; Jorm et al., 1997; Olsson \& Kennedy, 2010). From the analysis of questionnaires administered to a sample of British adults, Furnham (2009, p.525) concluded that 'lay people show a curious pattern on [sic] insight, ignorance and naivety with regard to the cause and cure of mental disorders. They appear to have a modestly realistic but somewhat naive view of the process and efficacy of psychotherapy. This may influence how they react to their own and others' mental illness.' 
Quantitative research using questionnaires to study popular attitudes towards psychotherapy has encountered various problems, such as difficulties in distinguishing between types and formats of therapy, but qualitative approaches are adding nuance and depth to findings (Coe, 2009). The postmodern turn to language, in tandem with a scepticism about essentialist assumptions in psychology, has necessitated a rethinking of the relationship between 'attitudes' and 'culture'. Edwards (1997) demonstrated how a close scrutiny of talk and text invites a re-examination of psychological concepts as discursive products. Instead of taking for granted the discipline’s capacity to uncover the building blocks of our intrapsychic and relational realities, we must wonder whether a parallel process is taking place: 'Psychology may simply elaborate...upon the conventional ways people are described in [a] particular society' (Potter \& Wetherell, 1987, p.103). These remarks can be seen as calling for an appreciation of common culture and its grounded aesthetics as a site where this occurs (Willis, 1990). To put it in more technical discursive psychology terms, 'mundane culture' can be seen as a fluid, dynamic site which makes available certain identity subject positions in relation to issues that are discursively negotiated, resisted and accomplished.

A premise of a social constructionist outlook is that knowledge evolves in the space between people, 'in the realm of the "common world” or the "common dance”" (Hoffman, 1992, p.8), and indeed, in this study, the 'common song'. Willis (1990) argues that pop songs mobilise discourses that play back to people their own experiences whilst providing a means of interpreting them. He believes music is not something that people simply like and do; it provides a model for their involvement in a common culture. Songs containing pronouns such as 'I' or 'we' enable listeners to read themselves into the lyrics and more or less transiently inhabit relevant identity positions and discourses. Murphey and Alber (1985) postulated a 'pop song register' and described it as the 'motherese' of adolescents, who are particularly prone to appropriating this 'ghost discourse' (Murphey, 1992), making sense of it in 
personally associative ways. Research attention has been paid to the ways in which songs construct social categories and contribute to and reinforce a 'cultural common sense' about those categories. For example, McKay (2013) considered how popular music has represented disability. However, research has not attended in a detailed way to how songs construct psychotherapy, although Pfister (1997) has credited popular music with reinforcing the selffocus of psychotherapy at a time (in the 1970s and 1980s) when the cultural profile of psychotherapy was raised and expanded.

An increasingly salient commentary on psychotherapy has been woven from other strands of popular culture. Gabbard (2001) argues that films constitute a storehouse of psychological images of our times, including portrayals of therapists who 'have endured cinematic depictions of their work personas that range from the buffoonish to the malevolent with very rare exceptions that approach what a therapist does in practice’ (Gabbard, 2002, p.4). TV series such as The Sopranos received attention from professional bodies, as evidenced by the decision of the American Psychoanalytic Association to bestow an award on the actress portraying the central protagonist's therapist for incarnating 'the most credible psychoanalyst ever to appear in the cinema or on television' (Gabbard, 2002, p.6). In contrast, the series In Treatment (2008-2011), which portrayed a therapist in session with his clients and culminated each week with a window into his own analysis, did not make a significant impression on psychotherapeutic sensibilities or academic research.

In light of these observations, the research presented in this paper examines how 'psychotherapy' and its linguistic/conceptual derivatives are constructed in the lyrics of pop songs and considers the discursive affordances and implications of these constructions. 


\section{Method}

\section{Data collection}

Given the immense number of popular songs, the process of sampling called for careful consideration. We developed an approach to data generation that was oriented towards producing a data set of maximum scope and credibility. We contacted 89 music industry executives from the USA, the UK, Canada and Greece as these are locations with substantial music markets in the English-speaking world and/or where we had personal contacts with people in the music industry. We asked them to use their online social networks to identify songs that explicitly referred to psychotherapy or psychotherapists. We primed them with a list of related terms such as 'psychoanalysis', 'psychiatry' and 'counselling' as well as common metaphors such as 'talking cure'. These music industry executives shared our request via social media, thereby seeking and obtaining input from an extensive pool of individuals. They then identified the most commonly-nominated songs from the responses they received and conveyed these to us. This can be seen as an approach to sampling via 'key informants’ who had privileged access to and experience of the research context (Gilchrist, 1992).

We received 63 suggestions for relevant songs, 33 of which did not make an explicit reference to the terms we were interested in but alluded to mental illness, distress and/or psychoactive drugs. As a final inclusion criterion, we considered commercial availability in order to discard songs that have not been released by a label and where the song's public profile would not have been augmented by formal marketing and promotion. As a result, 24 songs were analysed (see Appendix for a full discography). This process was geared towards obtaining what conversation analysts call a 'specimen perspective’ (see ten Have, 1999) - 
one that recognises that, in the face of a near-limitless pool of material, the analyst's aim must be to find typical rather than exceptional material (Taylor, 2001a).

The lyrics for the selected songs were obtained through various sources such as artists' webpages, online lyrics databases and CD booklets. We listened to the songs as many times as were required to ensure that accurate versions of lyrics were obtained. After several readings, we focused on the relevant passages of some songs while others necessitated a more holistic engagement in order to attend more fully to the discursive accomplishments at hand. This was determined case by case, decided by the extent to which the data were related to the topic of concern. Extra-textual information, such as sound effects and changes in pitch, tone and animator, was not attended to.

\section{Approach to data analysis}

In this study, we applied (most of) the stages of Foucauldian discourse analysis outlined by Willig (2013). This approach was chosen because of the alignment between the critical analytic commitments of the study and the concern of Foucauldian discourse analysis with 'dominant, hegemonic discourses [which] privilege versions of social reality that accord with and reinforce existing social structures and the networks of power relations associated with them' (Coyle, 2016, p.168). For examples of research that has productively used Foucauldian discourse analysis, see Spohrer (2011) and Willig (2011).

Each stage of analysis yielded insights that cumulatively built a complex analytic picture. The first stage involved a focus on discursive constructions, that is, the ways in which the discursive object ('psychotherapy') was constructed in the data. The second stage considered the wider discourses in which the discursive constructions of psychotherapy were located. The third stage concerned the action orientations of the discursive constructions. This involved asking what was being rhetorically achieved by constructing psychotherapy in 
particular ways at particular points in the data and how these constructions related to other constructions in the surrounding text. In this, we drew upon Potter's (1996) work on how the factuality of 'descriptions' is achieved. The fourth stage focused on the subject positions that were offered to performers and others by the discourses that were invoked in the lyrics and on what could be felt, thought and experienced by performers and audiences from within those subject positions. The fifth stage addressed practice and considered the ways in which the discursive constructions and the subject positions offered within them opened up or closed down opportunities for action. This analytic process departs from Willig’s (2013) original scheme only in respect of the fourth stage. The analytic focus specified above for that stage constitutes a separate sixth stage in Willig's scheme but it made more sense to consider the nature and affordances of subject positions together in one analytic stage (and addressed criticisms of Willig's sixth stage: see Walton, 2016). The kind of deconstruction undertaken in this paper would best be described as a strategy of reading texts which 'aims not to devalue the agency of the individual subject, but to locate it' (Parker, 1999) and is based on the assumption that popular cultural narratives both describe and construct psychotherapeutic realities which potentially influence not only clients and the wider systems they belong to but also psychotherapists themselves.

Through this analytic process, we developed several themes that constituted discursive constructions of psychotherapy. We crafted these through a consideration of patterns and motifs that we developed from our close, systematic inspection of the data. We chose three broad, overlapping themes as the most fruitful sites of inquiry. When we considered the patterns and motifs that made up these themes, we saw that they related to existing concepts ('banal nationalism’ and ‘the therapeutic relationship’) and deconstructive analytic concerns (that is, a search for how power operates in discourse) of which we were aware from our reading and previous research. We applied these concepts to the data patterns 
to generate theme titles that could relate to broader literatures while capturing local commonalities of construction.

As with any (qualitative) research, the analytic foci, process and outcomes arose from a dynamic interplay of the data and the researchers' subjectivities. Possibly the most relevant aspects of these subjectivities concern the first author's position as a counselling psychologist and his former role as a product manager for a major music label and the second author's position as a critical social psychologist and experienced qualitative researcher. These positions contributed to the generation and development of the research idea and foci. We both share social constructionism's view of language and discourse as crafting some possibilities for practice (such as the psychotherapeutic endeavour) and closing down others, and have consciously brought criticality into our reading of the data. In the analytic process, we worked collaboratively, seeking to generate persuasive, data-grounded interpretations and avoid idiosyncratic readings while respecting each other’s insights and expertise.

\section{Results}

Each of the three thematic clusters that were generated will now be outlined before grounding them in relevant data.

\section{'Banal therapy'}

Billig (1995, p.6) coined the term 'banal nationalism' to cover 'the ideological habits which enable the established nations of the West to be reproduced'. He identified ostensibly benign common practices such as flying a flag above a post office as effectively mobilizing national identity and imparting a sense of naturalness to the idea of the nation. In a similar vein, the first theme taps into discursive practices that signpost therapy innocuously, imbuing the 
category with a naturalizing force powerful enough to render it both sufficient and taken-forgranted in that further elaboration seems unnecessary. Perhaps it would be peculiar to find popular songs delving into the specifics of different therapeutic approaches, debating their efficacy or extolling their virtues. Nonetheless, this should not detract from the fact that psychotherapy can be constructed in monolithically banal terms which rely on a plethora of clichés that are discordant with the landscape of contemporary practice. Given the fact that we have not come across any song singing the praises of psychotherapy, this discursive object might be the closest to a positive construction of psychotherapy in popular music.

This theme is most evident in those songs that name-check and reproduce therapy without explicitly being geared towards a representation of it. The category 'therapy', including its practitioners, often appears to be marshalled in order to legitimise some sort of psychological issue. A pervasive discourse that facilitates the construction of 'banal therapy' finds human distress cast in pathologising terms. As the category 'therapy' crops up, it appears to be setting in motion a type of vocabulary typically associated with pejorative, psychiatrically-derived terms such as 'insane', 'crazy', 'neurotic', 'schizoid', and 'paranoid' among others. However, given that some of these words, most notably 'crazy', have entered the discourse of pop songs carrying connotations of romantic feelings and intense longing, it is best to avoid reading them in an unqualified stigmatising fashion.

\section{The 'non-therapeutic relationship'}

Virtually every current approach to psychotherapy places substantial emphasis on the relationship between therapist and client. Entire disciplines, such as counselling psychology, have grounded their practitioners' identities in a sustained relational and reflective engagement with clients, fostered by this concept. The nature of this therapeutic relationship has acquired a somewhat sacrosanct status within psychotherapy since it can provide grounds 
for theoretical integration in addition to an empirically supported construct to which therapeutic change is attributable (Clarkson, 2003; Cooper, 2008; Wampold, 2000). The data are characterised by a striking absence of the therapeutic relationship. Indeed a discourse of a 'Non-therapeutic relationship' between therapist and client constitutes a prominent theme. This could be further nuanced by attending to the facets of the 'Non-therapeutic relationship' as implicated in the data: financial exploitation, mystification, inauthenticity, omniscient proclamation and medicalisation are the five discursive strands that accomplish the 'Nontherapeutic relationship'.

\section{'I know therefore I can'}

The third and final discursive formation concerns intimately linked issues of knowledge and power and how they relate to psychic truth. If the first theme is understood as making available a subject position of somebody in need of therapy and the second as crafting the experience of being involved in a non-therapeutic relationship, this theme creates in more or less explicit ways a subject bereft of power to articulate their experience from a phenomenological point of view. The authority of knowing and naming feeling states is constructed as lying in the hands of expert practitioners utilising obscure diagnostic terms, with a concomitant prerogative to treat or 'correct' them. Therapy can come across as a powerful, oppressive tool of an austere social order that is intent on discipline and control; as such, resistance is a prominent discursive accomplishment in this theme. The theme is facilitated by a rhetoric which is argumentative and seeks to persuade (Billig, 1997), as it relies heavily on criticism and justification.

We now turn to the specifics of the song lyrics to illustrate how these themes are constructed across the data that we studied. As we were unable to obtain permission from publishers to reproduce substantial lyric extracts here, we invite readers to consult online 
song lyric databases to see the complete lyrics of each song. Even better, readers can consult 'youtube' lyrics videos to engage with the songs as musical as well as linguistic compositions. In what follows, we have italicised words and phrases taken from relevant song lyrics.

\section{Song 1: Charlotte Church/Crazy Chick (2005) $)^{1}$}

In this pop love song, therapy is flagged in the first line by means of a self-referral: "I think I'm gonna need some therapy / Oh babe I hope you've got a PhD”. The verb “need” constructs therapy as something that is needed rather than a relational experience which is considered and chosen. It is then associated with an academic title ("PhD”) suggestive of power and expertise, moving towards a representation of therapy in which the practitioner is a recognised expert. The subject is thus divested of power to decide whether therapy is desirable, as knowledge of the relational qualities it entails is obscured in favour of clichés (“leather couch”, “professional help”, “PhD”). This song is a good example of 'banal therapy’ as its unintended consequences involve a validation of therapy through unelaboration, thus rendering the category both natural and sufficient. A pathologising discourse signified by the words "insanity" and "crazy" shapes the meaning of the feelings of longing that the song alludes to. The category ‘therapy’ is marshalled in order to legitimize the artist's distress and longing towards her love object.

\section{Song 2: T-Pain feat. Kanye West/Therapy (2008)}

This rap song only mentions therapy in the chorus of its lengthy lyrics. It constructs a subject who needs to talk to someone about his relationship problems before concluding: "Shorty you ain't gotta be scared of me, all we need is therapy". "Shorty" is a term of endearment referring to his female partner and therapy is name-checked as the straightforward solution to their conflicts. "All we need is therapy” imbues the category 'therapy' with a sense of 
naturalness and omnipotence which both simplifies it and closes down considerations regarding its suitability, efficacy or complexity. Relationship problems are again legitimized by the mere mention of therapy, which is made banal by virtue of its un-elaboration.

\section{Song 3: James/Laid (1993)}

In this pop/rock composition we find another invocation of 'banal therapy', this time embodied by a banal therapist who appears only momentarily in the account to accomplish the name-checking function: "My therapist said not to see you no more /She said you're like a disease without any cure / She said I'm so obsessed that I'm becoming a bore, oh no." Although the song is not geared towards an elaborated representation of the female therapist, it constructs her as foregoing exploration of feelings by passing down a medicalised diagnosis and failing to foster a therapeutic relationship. The therapist omnisciently proclaims that the client's incurable disease is the object of his love, towards whom this song is addressed, and that he is so obsessed that he is "becoming a bore". The words "obsessed", "crazy", "disease” and "cure” cast distress in pathologising terms which render therapy appropriate as they invite a medical intervention. 'Banal therapy' in this song further functions to legitimize the erratic behaviours that the artist expresses later in the song.

\section{Song 4: Prince/Let’s Go Crazy (1984)}

This funk/pop song starts with a spoken segment. "Dearly beloved / We are gathered here today / To get through this thing called life." "Dearly beloved" summons a grand narrative as it is evocative of the opening of a religious minister's addresss. It continues: "So when u call up that shrink in Beverly Hills / You know the one - Dr. Everything'll-Be-Alright / Instead of asking him how much of your time is left / Ask him how much of your mind, baby”. These lines construct the enemy, condescendingly referred to as the "shrink" whose power is signified by an academic/medical title (“Dr.”). The cynical description “Dr. Everything'll-be- 
Alright” functions as a summative characterization derived from his presumed stereotypical responses, contingent upon a 'Non-therapeutic relationship', which are dismissed as inauthentic reassurance. Financial exploitation is worked up by "Beverly Hills”, a lavish area in California which invites associations with money and superficiality. The segment further paves the way for an unspoken omniscient proclamation in response to "how much of your mind [is left]". Medicalisation is achieved with the mention of "pills". As such, the text constructs the facets of the type of relationship that this wicked practitioner is accused of building with the "dearly beloved” who are cautioned against seeking his services.

This song exemplifies the third theme whereby the artist attempts to reclaim the power to heal by offering an alternative theory regarding human distress. A rhetorical antitherapy discourse is constructed on the grounds of a competing, superior framework in which existential issues and depressive feelings, symbolized by the descending “elevator”, can be addressed. This framework is one of surrealism meant to empower the audience to "go crazy”. Therapy is resisted as it is positioned antithetically to an attitude towards life as endorsed by the artist. When the artist says "hang tough children", a discursive split is accomplished between the world of powerful adults and "children" who are meant to resist a corrupt and hegemonic power. In addressing his audience as children the artist invites associations with innocence and malleability, positioning himself in the role of rescuer/leader of the resistance and subtly inoculating himself against accusations of leading the audience astray instead of saving it. We later encounter in the lyrics a polemic against the authority of the inauthentic expert who "will make everything go wrong”. This is boosted by a rhyming three-part list ("Pills and thrills and daffodils will kill”), and an extreme case formulation ("everything”), rhetorical devices which enhance the persuasiveness of the account (Jefferson, 1990; Pomerantz, 1986). Mockery, criticism and surrealism are the tools that underpin the resister's recalcitrant position. The text opens up two binary subject positions 
for listeners: they can either accept the preaching of the artist or dismiss it altogether; only one version of therapy can be afforded the status of truth. The artist attempts to persuade his audience that he both knows and can offer what they need - liberation. The 'Non-therapeutic relationship' in this song accommodates the third discursive object, for why would we need to resist psychotherapists if they actually helped people?

\section{Song 5: The Ramones/Psycho Therapy (1983)}

The word 'psychotherapy' is a portmanteau, deriving its meaning from the Greek words for soul ('psyche') and healing ('therapeia'). The title of this punk song splits the psychotherapy category, changing its meaning to imply that it is a treatment for 'psychos', a pejorative label for 'mentally ill' people. The song takes on an expositional, deconstructive dimension which is effective through its simplicity; it merely puts a gap between the two words to reveal their ‘true’ meaning. By repeating the line "Psycho Therapy / That's what they wanna give me”, two categories at war are invoked: the subject vs. "they". A pathologising discourse runs through the song with terms such as "schizoid”, "nuthouse”, and "psycho zone” constructing behaviour and experience in medical, perilous, and socially transgressive terms. "Tuinal” refers to a sedative that is now discontinued, which at the time was also used as a recreational drug. The "dope fiend" who will "burglarize your home" and "kill someone" constructs the subject in need of therapy as a menace to society which needs to be disciplined, punished and restrained through therapy. The singer's threats engender bold declarations of mal-intent, a rebellion against a society and a moral order that he constructs as holding similar values to therapeutic practitioners. In this song, the third theme ('I know therefore I can') is turned on its head as the narrator claims knowledge of what is 'wrong' with him, choosing to unleash his power to the detriment of the status quo. 


\section{Song 6: The Avalanches/Frontier Psychiatrist (2000)}

This electro song was the most frequently suggested track by the key informants whom we consulted. It starts with a dialogue concerning a schoolboy, Dexter, between his mother and a male school authority figure. Dexter's "truancy problem” is cast in a pathologising discourse of insanity which is ascribed by consensus. The latter is rhetorically achieved by extreme case formulations afforded by repeating the word "entire".

The chorus is performed in a rap style and repeats the prescription "that boy needs therapy", the term "psychosomatic" inviting associations with medical treatments as opposed to just talking. "Lie down on the couch, what does that mean? You're a nut! You're crazy in the coconut!" constructs the subject who lies on the couch as 'insane', effectively pathologising truancy; its meaning and emotional impact on Dexter are left unexplored. As "expulsion is the only answer", the therapy that this boy needs becomes attached to a process of rejection/exclusion rather than containment and integration.

In the middle eight part (an eight-bar section in the middle of a song that has a different melody from the rest of the song), we find a stream-of-consciousness narrative which is presumably Dexter's unconscious material emerging through hypnosis. The use of the word "frontier" to characterise the titular psychiatrist points to the division between conscious and unconscious mental life. The free associations culminate in sexualised discourse, with a reference to genitals being suppressed. The account mystifies the relationship between Dexter and the psychiatrist by virtue of its narrative structure as well as its evocative content. It does so by drawing on psychoanalytic insights pertaining to sexuality, unconscious communication and hypnosis, thus fusing technique, process and content into an account that is hard to dispute, in part because nothing is sufficiently articulated. This might also constitute a banal/clichéd representation of psychoanalysis which 
is presented in simplified and sensationalist terms, although arguably the impact of this construction is mediated by listeners' familiarity with the concepts.

The absence of Dexter's un-hypnotized voice warrants a reading of this text as constitutive of a certain kind of power hierarchy. The schooling system is the site in which issues of therapeutic power between the world of disciplining adults and unruly children are played out. The school authority and the "frontier psychiatrist" hold both the power and the knowledge to subject Dexter to a dehumanising treatment that bears none of the features of a therapeutic relationship. We are not given a phenomenological account of Dexter's experience, an omission that constructs a subject bereft of power to articulate thoughts and feelings. When Dexter eventually speaks, it appears that he has no control over what he says: "I promised my girlfriend I'd...violin". Thus the account highlights issues of agency and resistance as it implicitly questions the extent to which he has consented to the treatment.

Again, the 'Non-therapeutic relationship', this time having moved well beyond financial exploitation and into abusive territory, paves the way for the theme of ' $\mathrm{I}$ know therefore I can' as it invites the listener to inhabit one of two subject positions: to acquiesce in what Dexter is being subjected to or resist the power/knowledge of the 'experts'.

\section{Song 7: Melanie Safka/Psychotherapy (1970)}

This playful folk song turns psychoanalytic discourse on its head by parodying Freudian drive theory and psychosexual development, and their claims to truth when it comes to freedom from impulses. The chorus goes: “Glory glory psychotherapy, glory glory sexuality / Glory glory now we can be free as the id goes marching on”. Freudian dogma, along with the power to reveal unconscious truths, are undermined in the chorus which mockingly glorifies psychoanalysis from the inside, using its own terms to critique the obscurity of its claims. The song is sung to the tune of the 'Battle Hymn of the Republic', an American Civil War- 
era marching anthem evoking patriotic feelings. This linguistic and auditory configuration further parodies the idea of an "id marching on" towards either freedom or truth. In this song, 'I know therefore I can’ refers to the singer's ability to expose psychotherapy as nonsense by appropriating insider knowledge to the effect of subverting it.

\section{Discussion}

In this paper we have offered insights into the discursive possibilities that are afforded by the term 'psychotherapy' and its linguistic/conceptual derivatives in the lyrics of pop songs. The study has several limitations that must be acknowledged. Firstly, it has only identified discursive objects in the English language. Secondly, even though most genres of popular music are represented in the data set, the songs do not carry equal weight in terms of their cultural resonance and enduring recognisability. Thirdly, we have deliberately bracketed historical context in our analysis in order to discuss the discursive accomplishments as culturally available positions in an analytic present. In other words, in line with the research aims, we were primarily concerned with how therapy is currently constructed in popular music through timeless as well as contemporary songs. A genealogical approach tracing historical shifts in how vocabularies are galvanized by 'psychotherapy' in popular music discourse would yield insights that are more attentive to the history of psychotherapy as an institution. It would also be able to connect with more formal critiques of psychotherapy, whilst exposing the ways in which it has been fused with psychoanalysis and psychiatry (Laing, 1967; Szasz, 1974). These foci that were set aside in the present study offer potentially valuable routes for future research on the construction of psychotherapy in pop songs and more broadly in popular culture.

Reflecting on the insights generated by the present study, it is worth emphasising that phrases such as ‘you need therapy’ or 'seek professional help’ have become common features 
of Western parlance. They can be uttered in diverse ways, ranging from the jovial to the accusatory and the stigmatising, and are indicative of an enduring image of psychotherapy as a legitimate avenue for tracing and ameliorating 'psychological problems'. What is most interesting is that this colloquial quasi-referral can be made by anyone, including the person who considers themselves in need of therapy. In other words, from a popular discourse point of view, there is no privileged subject position, no necessary category entitlements that need to be worked up for someone to make this claim. Such statements, however, are intimately connected with the discursive practices that sustain them and are sustained by them. One consequence of such accounts is that a particular, albeit nebulous account of therapy is invoked vis-à-vis a behavioural, intrapsychic and/or interpersonal problem, which the present analysis has identified as 'banal therapy' - a ubiquitous discursive object in popular song discourse. This lends some validity to Furnham’s (2009) findings on lay conceptions and representations of psychotherapy, even as it opens up analytic space for the discursive exploration of 'mental health literacy'. The pathologising discourse encountered in this theme resonates with the lay misuse of mental health terms: deploying the language of clinical diagnosis to describe everyday personality traits (Kelly \& Winterman, 2013) is a common practice. Furthermore, the categories 'therapy' and 'therapist' spring up in the discourse of pop songs close to descriptions of distress rendered in pejorative, pathologising, psychiatrically-derived diagnostic language.

Gabbard's (2001) remarks on the popular representations of therapists in movies could also be applied to their construction in pop songs. If one understands the 'Nontherapeutic relationship’ as distorted exaggerations of qualities that therapists could conceivably demonstrate, then we should wonder whether other attributional processes are also at play. More specifically, given that the therapists in the data are consistently presented from the client's point of view, thus obscuring their subjectivity to the point of dehumanising 
them, it is worth considering the facets of the 'Non-therapeutic relationship' as projections of unfavourable attributes onto therapists in an effort to evacuate them from the subject that discursively evokes them. Interestingly, this process is often encountered in psychodynamic approaches, whereby the client disowns anxiety-provoking affect by locating it in the therapist. From a discourse analytic point of view, this is also understood as serving the functions of blaming and exoneration.

The third theme, entitled 'I know therefore I can', suggests that two forms of power operate within discursive constructions of psychotherapy in pop songs. The first concerns the power of expertise assigned to psychotherapists which allows them to label 'dysfunctional' psychological states, with a derivative prerogative to correct them. Social sanctioning thus imbues psychotherapists with knowledge and power pertaining to human distress. In parallel, the theme further illustrates the power of the lay person to resist such 'expert knowledge' through mockery, social transgression, critique and/or rhetoric. As such, insofar as therapeutic knowledge is concerned, power emerges as a bilateral dynamic that involves both wielding and submission. Discourse analysis aligned with Foucauldian thinking outlines how people subjugate themselves to disciplinary forms of power, while enabling a deconstruction of the ways in which they allow themselves to be understood in those terms. The notion of 'banal therapy’ speaks volumes about how subtly the power inherent in linguistic constructions can extend and legitimise disciplinary control. Psychotherapy does not exist in a social vacuum; it is intimately linked with spheres of influence such as politics and education. Popular music might seem too innocuous a medium to be included in inquiries into the interrelatedness of the above - an inconsequential, if not variably enjoyable, speck against a backdrop of disciplinary regimes disseminating languages of psychological description. To bring forth an analogy from popular music, we understand the function of the discursive objects identified in this paper as hegemonic and as tantamount to that of bass 
lines in pop songs - muted to the untrained ear and likely to be lost within the gestalt of the whole song and its idiosyncratic meaning for the individual listener, yet nonetheless always there and with surprisingly limited variation. Our analysis, thus, does not purport to have identified the 'messages' that pop music discourse conveys about psychotherapy but rather to have interrogated (some of) the riffs upon which such narratives are constructed. Given that cultural products emerging from the music industry often bear closer resemblance to the values of countercultures than to those of the corporate elite (Crane, 1992), their inclusion in social constructionist research would be a timely rectification of an analytic oversight.

Psychoanalysis, psychiatry and generic counselling are the three discernible modalities in the data which are undermined through a discursively accomplished banality on the grounds of the non-therapeutic ways in which their practitioners operate. This observation suggests that insofar as popular music is concerned, differentiation between schools of therapy is irrelevant. Rather what subsumes and obscures the boundaries between distinct ways of practice is something akin to a grand narrative. This might be useful to hold in mind for those psychotherapists unduly concerned with popularising the nuances of their professional identity.

The discursive objects identified in this paper show little sensitivity to issues of inconsistency and variation (Potter \& Wetherell, 1987; Taylor, 2001b). Whether this is indicative of the monolithic positions made available by the discursive objects, suggestive of an analytic blindspot, or a structural feature of popular music discourse is open to debate. An expert consultant on the Israeli series BeTipul, which spawned the American adaptation In Treatment, notes: 'I realized that the shortcomings and failures of analysts are essential to good drama' (Baht, 2010, p.235). Equally, psychotherapeutic incarnations in the lyrics of popular songs could be read as attempts to maintain a sense of aural dramaturgy in casting therapists in the role of villains. The image of the expert, callous therapist is pervasive, 
making the absence of other metaphors such as the 'wounded healer' (Rice, 2011) all the more problematic. McWilliams (2005) laments what she perceives as the devouring of psychotherapy by commercial culture, the very institution from which it was meant to maintain a critical distance. She notes how the metaphor for the therapist seems to have shifted from 'healer' to that of 'technician', 'redefining the complex project of psychotherapy in terms of the most simple-minded notions of how one person influences another and subordinating the therapist's humanity to the interests of social control and short-term cost saving’ (p.143). She continues: ‘even in my own practitioner-oriented graduate program, one encounters versions of the myth that the independent practitioner hangs out a shingle, rakes in the money, fosters an unnecessary dependency that keeps the cash cows coming back, and is accountable to no one' (p.146). Interestingly, popular culture references also emerge in the consulting room, raising new clinical questions (Robinson \& Gordon, 2008) and turning the relationship between clinical encounter and sociocultural context into a mutually constitutive process where both stand to be examined vis-à-vis the other.

Popular music is not amenable to a transmission model of communication. The supremely interactional nature of live performances, the socio-politically attuned nature of music journalism as well as the proliferation of digital social media and interactive music platforms are some of the factors mediating the discursive objects identified in this study. Young and Collins (2010) point to a marked increase in participatory culture where audiences become producers of or collaborators in popular songs. This is also evident in the commentary accommodated by online music video platforms such as 'youtube', whereby snippets of ideologically pregnant discourse (comments) recreate anew, extend or resist disciplinary control, thereby querying whether modern audiences are the inhabitants or the architects of the identified subject positions. Inter-disciplinary research drawing on insights from psychology, sociology and cultural studies is a direction that this paper hopes to 
encourage in an attempt to tease out how popular culture frames how psychotherapy is talked about in such platforms before examining how it operates in institutional settings such as schools and mental health services.

In addressing constructions of psychotherapists, this paper also invoked constructions of clients implicated in the subject matter. The latter can occupy subject positions within a dualistic construction of psychotherapy, expressed along binaries such as helpful/harmful, empowering/oppressive and omnipotent/ irrelevant. Of course, therapeutic work should be able to move beyond and be creative with them. The identified discursive objects, however, are also triangulated with the systems that clients belong to (families, peers) and it is in that locale where they might thwart therapy's curative aims by devaluing it, as it gets recreated in banal, non-therapeutic and disempowering terms. This especially impedes those strands of psychotherapy that have shifted from treating clients as the objects of intervention into understanding them as the subjects of experience (Danziger, 1990). It further impoverishes attempts to attract into training practitioners who are eager to adopt a reflexive stance of 'being with’ rather than 'doing something to' clients. If we entertain the idea of therapy as social construction and accord value to the position of 'not knowing' and its relevance to the notion of a therapeutic conversation (McNamee \& Gergen, 1992), then this paper can contribute to discussions of the interplay between social and medical lexicons of human distress. On the other hand, from a practitioner's point of view, there is a refreshing quality to these rebellious, mocking or 'ignorant' discourses. Irreverence might afford a discipline what, according to Slide (2007), political incorrectness affords a nation, that is, a sense of history to help us understand ourselves better. It is important to have a vehicle and a vocabulary to criticise, mock and deconstruct what is precious to us. Otherwise our own self-sustaining discourses will elevate it to an uncritical, idealised level from which it might further oppress those whom it purports to help. 


\section{Notes}

${ }^{1}$ Artist's name/Song title (year of original release).

\section{References}

Baht, R. (2010). A psychologist across the lines: Consulting for the TV series Betipul [In Treatment]. Contemporary Psychoanalysis, 46(2), 235-249.

Billig, M. (1995). Banal nationalism. London: SAGE.

Billig, M. (1997). Discursive, rhetorical, and ideological messages. In C. McGarty \& S. Haslam (Eds), The message of social psychology: Perspectives on mind in society (pp. 3653). Oxford: Blackwell.

Bor, R., \& Watts, M. (Eds) (2017). The trainee handbook: A guide for counselling and psychotherapy trainees ( $4^{\text {th }}$ edn.). London: SAGE.

Bugental, J.F.T. (1992). The art of the psychotherapist. New York: Norton.

Clarkson, P. (2003). The therapeutic relationship ( $2^{\text {nd }}$ edn.). London: Whurr.

Coe, N. (2009). Critical evaluation of the mental health literacy framework using qualitative data. International Journal of Mental Health Promotion, 11(4), 34-44.

Cooper, M. (2008). Essential research findings in counselling and psychotherapy. London: SAGE.

Coyle, A. (2016). Discourse analysis. In E. Lyons \& A. Coyle (Eds), Analysing qualitative data in psychology ( $2^{\text {nd }}$ edn.) (pp. 160-181). London: SAGE.

Crane, D. (1992). The production of culture: Media and the urban arts. London: SAGE.

Danziger, K. (1990). Constructing the subject: Historical origins of psychological research. Cambridge: Cambridge University Press.

Edwards, D. (1997). Discourse and cognition. London: SAGE.

Furnham, A. (2009). Psychiatric and psychotherapeutic literacy: Attitudes to, and knowledge of, psychotherapy. The International Journal of Social Psychiatry, 55(6), 525-537.

Furnham, A., Daoud, Y., \& Swami, V. (2009). 'How to spot a psychopath’: Lay theories of psychopathy. Social Psychiatry and Psychiatric Epidemiology, 44(6), 464-472. 
Furnham, A., \& Wardley, Z. (1990). Lay theories of psychotherapy I: Attitudes toward, and beliefs about, psychotherapy and therapists. Journal of Clinical Psychology, 46(6), 878-890.

Gabbard, G. O. (2001). Introduction. In G. O. Gabbard (Ed.), Psychoanalysis and film (pp. 116). London: Karnac.

Gabbard, G. O. (2002). The psychology of The Sopranos. New York: Basic Books.

Gilchrist, V. J. (1992). Key informant interviews. In B. F. Crabtree \& W. L. Miller (Eds), Doing qualitative research: Research methods for primary care (pp. 70-89). Thousand Oaks, CA: SAGE.

Goodheart, C. D., Kazdin, A. E., \& Sternberg, R. J. (Eds) (2006). Evidence-based psychotherapy: Where practice and research meet. Washington, DC: American Psychological Association.

Hoffman, L. (1992). A reflexive stance for family therapy. In S. McNamee \& K. J. Gergen (Eds), Therapy as social construction (pp. 7-24). Thousand Oaks, CA: SAGE.

Howard, S. (2010). Skills in psychodynamic counselling and psychotherapy. London: SAGE. Jefferson, G. (1990). List construction as a task and resource. In G. Psathas (Ed.), Interaction competence (pp. 63-92). Lanham, MD: University Press of America.

Jorm, A. F. (2000). Mental health literacy: Public's knowledge and beliefs about mental disorders. British Journal of Psychiatry, 177, 396-401.

Jorm, A. F., Korten, A. E., Jacomb, P. A., Christensen, H., Rodgers, B., \& Pollitt, P. (1997). 'Mental health literacy': A survey of the public's ability to recognise mental disorders and their beliefs about the effectiveness of treatment. Medical Journal of Australia, 166(4), 182186.

Kelly, J., \& Winterman, D. (2011, October 10). OCD, bipolar, schizophrenic and the misuse of mental health terms. BBC News Magazine. Retrieved from

http://www.bbc.co.uk/news/magazine

Laing, R. D. (1967). The politics of experience and the bird of paradise. London: Penguin.

Lilienfeld, S. O. (2012). Public skepticism of psychology: Why many people perceive the study of human behavior as unscientific. American Psychologist, 67(2), 111-129.

McKay, G. (2013). Shakin’ all over: Popular music and disability. Ann Arbor, MI: University of Michigan Press.

McLeod, J. (2013). An introduction to counselling (5 ${ }^{\text {th }}$ edn.). Maidenhead: Open University Press.

McNamee S., \& Gergen K. J. (1992). Introduction. In S. McNamee \& K. J. Gergen (Eds), Therapy as social construction (pp. 1-6). London: SAGE. 
McWilliams, N. (2005). Preserving our humanity as therapists. Psychotherapy: Theory, Research, Practice, Training, 42(2), 139-151.

Murphey, T. (1992). The discourse of pop songs. TESOL Quarterly, 26(4), 770-774.

Murphey, T., \& Alber, J. L. (1985). A pop song register: The motherese of adolescents as affective foreigner talk. TESOL Quarterly, 19(4), 793-795.

Olsson, D., \& Kennedy, M. (2010). Mental health literacy among young people in a small US town: Recognition of disorders and hypothetical helping responses. Early Intervention in Psychiatry, 4(4), 291-298.

Parker I (1999). Deconstruction and psychotherapy. In I. Parker I (Ed.), Deconstructing psychotherapy (pp. 1-18). London: SAGE.

Pfister, J. (1997). On conceptualising the cultural history of emotional and psychological life in America. In J. Pfister \& N. Schnog (Eds.), Inventing the psychological: Toward a cultural history of emotional life in America (pp. 17-63). New Haven, CN: Yale University Press.

Pomerantz, A. M. (1986). Extreme case formulations: A new way of legitimating claims. Human Studies, 9(2-3), 219-229.

Potter, J. (1996). Representing reality: Discourse, rhetoric and social construction. London: SAGE.

Potter, J., \& Wetherell, M. (1987). Discourse and social psychology: Beyond attitudes and behaviour. London: SAGE.

Rice, C. A. (2011). The psychotherapist as 'wounded healer': A modern expression of an ancient tradition. In R. H. Klein, H. S. Bernard, \& V. L. Schermer (Eds), On becoming a psychotherapist: The personal and professional journey (pp. 165-189). New York: Oxford University Press.

Robinson, S., \& Gordon, G. (2008). Projecting inside: How can popular culture be used to amplify or influence the therapeutic narrative in the consulting room? Psychodynamic Practice, 14(2), 181-192.

Slide, A. (2007). Incorrect entertainment. Albany, GA: Bear Manor Media.

Spohrer, K. (2011). Deconstructing ‘aspiration': UK policy debates and European policy trends. European Educational Research Journal, 10(1), 53-63.

Szasz, T. (1974). The ethics of psychoanalysis: The theory and method of autonomous psychotherapy. New York: Basic Books.

Taylor, S. (2001a). Locating and conducting discourse analytic research. In M. Wetherell, S. Taylor \& S. J. Yates (Eds), Discourse as data (pp. 5-48). London: SAGE. 
Taylor, S. (2001b). Evaluating and applying discourse analytic research. In M. Wetherell, S. Taylor \& S. J. Yates (Eds), Discourse as data (pp. 311-330). London: SAGE.

Ten Have, P. (1999). Doing conversation analysis: A practical guide. London: SAGE.

Walton, C. (2016). Doing discourse analysis. In E. Lyons \& A. Coyle (Eds), Analysing qualitative data in psychology (2nd edn.) (pp. 182-201). London: SAGE.

Wampold, B. E. (2000). Outcomes of individual counseling and psychotherapy: Empirical evidence addressing two fundamental questions. In S. D. Brown \& R. W. Lent (Eds), Handbook of counseling psychology ( $3^{\text {rd }}$ edn.) (pp. 711-739). New York: Wiley.

Willig, C. (2011). Cancer diagnosis as discursive capture: Phenomenological repercussions of being positioned within dominant constructions of cancer. Social Science \& Medicine, 73(6), 897-903.

Willig, C. (2013). Introducing qualitative research in psychology ( $3^{\text {rd }}$ edn.). Maidenhead: McGraw Hill/Open University Press.

Willis, P. (1990). Common culture: Symbolic work at play in the everyday cultures of the young. London: Open University Press.

Young, S., \& Collins, S. (2010). A view from the trenches of Music 2.0. Popular Music and Society, 33(3), 339-356. 


\section{Appendix: Discography}

1. All Time Low. (2009). “Therapy”. Nothing Personal, Hopeless / Universal.

2. Avalanches, The. (2001). "Frontier psychiatrist”. Since I Left You, XL Records.

3. Briggs, The. (2003). "Head shrink, dead shrink”. Numbers, Disaster Records.

4. Church, Charlotte. (2005). “Crazy Chick”. Tissues and Issues, Sony Music.

5. Damned, The. (1980). “Therapy”. The Black Album, Castle Music.

6. Deadstar Assembly. (2003). “Therapy scares me”. Deadstar Assembly, Adam A. DeArborn.

7. Dream Theatre. (2002). “The test that stumped them all (Part IV)”. Six Degrees of Inner Turbulence, Warner.

8. Freudiana. (1990). "Sects Therapy”. Freudiana, EMI.

9. Green Day. (1994). "Basket case”. Dookie, Reprise / Warner.

10. Guetta, David feat. Kid Cudi. (2009). "Memories”. One Love, EMI.

11. Harvey, P.J. (2004). “The Darker Days of Me \& Him”. Uh Huh Her, Island.

12. James. (1993). “Laid”. Laid, Mercury.

13. Mitchell, Joni. (1974). “Twisted”. Court and Spark, Asylum / Warner.

14. Morissette, Alanis. (1997). “The Couch”. Supposed Former Infatuation Junkie, Maverick / Warner.

15. Nozuka, Justin. (2007). “Mr. Therapy Man”. Holly, Glass Note.

16. Oasis. (1995). "Headshrinker”. Definitely Forever, Creation.

17. Prince. (1984). "Let’s go crazy”. Purple Rain, Rhino / Warner.

18. Ramones, The. (1983). "Psycho Therapy”. Subterranean Jungle, Warner.

19. Safka, Melanie. (1970). "Psychotherapy”. Leftover Wine, Buddah Records.

20. System of a Down. (2002). “Chic 'n' Stu”. Steal this album!, Sony Music.

21. T-Pain feat. Kanye West. (2008). “Therapy”. Thr33 Ringz, Sony Music.

22. Tucker, Nancy. (1993). "Everything reminds me of my therapist”. Treasures from the Attic, Music Design.

23. Wintersleep. (2008). "Dead letter \& the infinite yes”. Welcome to the night sky, 147 Records.

24. Wright, Abdel. (2005). "Loose we now”. Abdel Wright, Interscope / Universal. 